\title{
The Interplay Among Levels of Personality:The Mediator Effect of Personal Projects Between the Big Five and Subjective Well-Being
}

Article in Journal of Happiness Studies · January 2012

DOI: $10.1007 /$ s10902-012-9326-6

CITATIONS

16

4 authors:

Isabel Albuquerque

University of Coimbra

10 PUBLICATIONS 58 CITATIONS

SEE PROFILE

\section{Marcela Matos}

University of Coimbra

76 PUBLICATIONS 840 CITATIONS

SEE PROFILE
READS

324

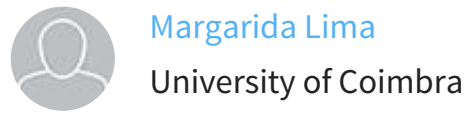

48 PUBLICATIONS 924 CITATIONS

SEE PROFILE

\section{Cláudia Figueiredo}

University of Aveiro

11 PUBLICATIONS 63 CITATIONS

SEE PROFILE

Some of the authors of this publication are also working on these related projects:

NoHoW - EVIDENCE-BASED ICT TOOLS FOR WEIGHT LOSS MAINTENANCE -- http://nohow.eu/ View project

Project Compassionate Schools View project 


\title{
The Interplay Among Levels of Personality: The Mediator Effect of Personal Projects Between the Big Five and Subjective Well-Being
}

\author{
Isabel Albuquerque • Margarida Pedroso de Lima • Marcela Matos • \\ Cláudia Figueiredo
}

(C) Springer Science+Business Media B.V. 2012

\begin{abstract}
Comprehensive models of personality aspire to integrate the several aspects related to the study of personality in a coherent whole. One of the great research challenges in this field is to understand if and how different levels of personality analysis interrelate to promote human well-being. The aim of the present study is to explore the mediator effect of personal projects' efficacy on the relationship between Big Five and subjective wellbeing (SWB) components. We conducted a cross-sectional study in which a battery of selfreport questionnaires was used to assess personality and SWB in 396 teachers. Path analysis results indicated that personal projects' efficacy fully mediated the effects of openness to experience, agreeableness and conscientiousness on life satisfaction and on negative affect. The effects of neuroticism, openness to experience, agreeableness and conscientiousness on positive affect were direct but also indirect, partially mediated by personal projects' efficacy. Neuroticism had a direct and an indirect effect through a decreased personal projects' efficacy on the three components of SWB. Extraversion only directly predicted increased positive affect. These findings corroborate the conceptualization that these two types of personality analysis units (Big Five and personal projects) have their own direct, unique and irreducible effect on life satisfaction, positive affect and negative affect. However, their impact on SWB components seems to be also explained through their effect upon personal projects' efficacy.
\end{abstract}

Keywords Personality · Big Five · Personal projects' efficacy ·

Subjective well-being

\footnotetext{
I. Albuquerque ( $₫)$

Faculty of Psychology and Education Sciences, University of Coimbra, Rua do Colégio Novo, Apartado 6153, 3001-802 Coimbra, Portugal

e-mail: ialbuquerque.ialbuquerque@gmail.com

M. P. de Lima · M. Matos

Cognitive and Behavioral Research Centre (CINEICC), Faculty of Psychology and Education

Sciences, University of Coimbra, Coimbra, Portugal

C. Figueiredo

Faculty of Psychology and Education Sciences, University of Coimbra, Coimbra, Portugal
} 


\section{Introduction}

Sheldon (2004) suggests that the study of personality may be one of the most important for understanding optimal human well-being. In the last years, authors in personality arena have developed comprehensive models that aimed to integrate the several aspects related to the study of personality in a coherent whole (McCrae and Costa 1996; McAdams 1995; Mischel 2004; Roberts and Wood 2006). These models allow us to explore the relationship between personality and well-being in a holistic and multi-level perspective.

The integrative framework proposed by McAdams is a well-received approach in this realm and has inspired others authors in personality psychology in the past decade (Little 1996, 2004, 2007; Sheldon 2004, 2007, 2009; Singer 2005). McAdams and collaborators have been, successively, improving and enlarging the model (Hooker and McAdams 2003; McAdams 1995, 1996, 2009; McAdams and Adler 2006; McAdams and Olson 2010; McAdams and Pals 2006). However, this hierarchical framework has always preserved the essential premise that the study of personality can be organized in three levels: dispositional traits, characteristic adaptations and integrative life narratives. McAdams and Pals (2006) stressed that each of these three levels of analysis provides independent information about the person, since each level is not reducible to others levels.

Although McAdams argues that the three different levels don't work together as an organized and integrated structure (McAdams and Adler 2006), he also suggests that, in the developmental course, life stories are layered over goals, and goals are layered over traits. Thus, it is expected "that dispositional traits, characteristic adaptations, and narrative identity should relate to each other in complex, meaningful, and perhaps predictable ways" (McAdams and Olson 2010, p. 530). Moreover, Little and Joseph (2007, p. 376) consider that it 3 is "in the interplay between enduring structures and dynamic processes, between inner processes and external contexts, that some of the most distinctive and intriguing features of being human are revealed".

Even though authors don't have a definitive idea about the implications of the relations between several levels of personality, we know that there may not be a perfect consistence and coherence between the three levels of personality. So, despite goals sometimes connect thematically to traits, often they do not and may contradict them (McAdams and Olson 2010). Sheldon (2004) suggests that it is important to consider the linkages between the different levels in McAdams' model and to observe if coherences or inconsistencies between them influence well-being. Furthermore, Little (1996, 2000, 2007) suggests that individuals may occasionally act out of character (free traits), for example, an introvert can act in an extraverted way, in an effort to deal with the context, even though this may have costs to his well-being. Some previous research indicates that the concordance between goals and traits can have positive implications on well-being (Brunstein et al. 1998; Diener and Fujita 1995; McGregor et al. 2006; Sheldon 2002, 2007; Sheldon and Kasser 1998).

Our position regarding the conceptualization of the linkages between traits and goals on production of well-being is that goals can be one way through which traits influence well-being, that is, we conceive goals as mediators on the relationship between traits and well-being. The current study aims to corroborate this perspective.

\section{The Big Five}

In the context of dispositional traits, Five Factor Model (FFM), also known by Big Five is, presently, a broad and consensual approach that has demonstrated a significant generality 
and applicability, through other and self evaluations (McAdams 1992, 1995; McAdams and Olson 2010). The FFM is defined as a hierarchical structure of personality traits that includes five basic bipolar dimensions: Neuroticism, Extraversion, Openness to Experience, Agreeableness, and Conscientiousness (Costa and McCrae 1992; McCrae and John 1992, Costa and McCrae 2008; McCrae and Costa 2008a, b). Costa and McCrae (1992, p. 2) defining these five personality domains considered that: "Neuroticism (N) assesses adjustment versus emotional stability. Identifies individuals prone to psychological distress, unrealistic ideas, excessive cravings or urges, and maladaptive coping response. Extraversion (E) assesses quantity and intensity of interpersonal interaction; activity level, need for stimulation; and capacity to joy. Openness (O) assesses proactive seeking and appreciation of experience for its own sake; toleration and exploration of the unfamiliar. Agreeableness (A) assesses the quality of one' interpersonal orientation along a continuum from compassion to antagonism in thoughts, feelings, and action. Conscientiousness (C) assesses the individual's degree of organization, persistence, and motivation in goaldirected behavior. Contrasts dependable, fastidious people with who are lackadaisical and sloppy."

Each of these factors represents the common variance among a large set of more specific thirty traits or facets. Theoretically, facets contain valid specific variance (Costa and McCrae 2008) and they can give detailed information beyond the five factors (McCrae and Costa 2008a). Recently, Albuquerque et al. (2012) have empirically supported this premise.

Research has suggested that these personality dimensions emerge in different cultures (McCrae and Costa 1997), that there is a continuum in the medium level of traits from adolescence to old age (McCrae et al. 1999) and that gender differences occur homogeneously across diverse cultures (Costa et al. 2001). Consequently, McCrae and Costa (2003) conceived the Big Five to be biological rooted dispositions that characterize the entire human species. Evolutionary psychology has supported this premise (Buss 1995, 2009).

\section{Personal Projects}

Personal projects are integrated in the level of characteristic adaptations in McAdams' model, jointly with a set of other personal action constructs linked to our motivational and intentional live (Little 2007), such as current concerns (Klinger 1975, 1977), personal strivings (Emmons 1986), and life tasks (Cantor and Kihlstrom 1987). Personal projects are extended sets of personally salient action in context, ranging from daily doings (e.g., to correct English tests of my students) to self-defining passions of life time (e.g., release my people) (Little and Chambers 2004). Little (1996, 2000, 2006) argues that personal projects connect internal motivational propensities and external ecological obstacles and affordances, capturing intentional action in context and the dynamics and impacts of action. McCrae and Costa (2003, p. 221) refer that "one advantage of personal projects as units of analysis is that they provide a detailed specification of the life structure at a single time, one that is phenomenologically real to the individual."

Human flourishing, in a personal project analytic view, encompasses the sustainable pursuit of core projects (Little and Chambers 2004). Little considers that "individuals experience well-being to the extend that they are engaged in personal projects that they appraise as estimable, meaningful undertakings, that are manageable, that are both supported by and redound to the benefit of others, and that are positive and rewarding". (2007, 
p. 40). The social ecological model proposes that personal projects features have a direct effect on well-being and interact with traits and contextual factors in the production of well-being (Little 2008).

\section{Subjective Well-Being}

Subjective well-being (SWB) is a multidimensional construct that involves a cognitive component, related to how we evaluate our life satisfaction (life satisfaction), and an affective component, concerning our positive or negative emotional reactions (respectively positive and negative affect) (Diener 1984; Diener and Lucas 1999). The SWB should reflect the experience of a high level of positive affect, a low level of negative affect and a high degree of satisfaction with one's life (Deci and Ryan 2008; Diener 2000; Diener et al. 2002). Research corroborates the premise that these three components are moderately correlated and relatively independent (Albuquerque et al. 2012a).

The subjective element of well-being reflects the researchers' conviction that social indicators, by themselves, do not characterize quality of life (Diener and Suh 1997, 1998) and that people respond differently to the same circumstances, and appraise conditions based on their distinctive expectations, values and previous experiences (Diener et al. 1999).

Research in SWB arena has attempted to investigate its predictive variables, to evaluate its consequences to physical and mental health, to determine its structure and measurement, to compare its levels across different countries, to study its physiological mechanisms, to observe the adaptation across time to events that influence it, and to develop strategies to promote it (Diener 1984; Diener et al. 1999; Eid and Larsen 2008; Kahneman et al. 1999).

\section{Big Five, Personal Projects and Subjective Well-Being}

A review conducted by Ozer and Benet-Martínez (2006) suggests that personality is a major predictor of significant life outcomes, namely SWB. Moreover, SWB has been considered as the perfect territory to explore the problematic of personality coherence (Pavot et al. 1995). Several studies have shown that both Big Five and personal projects are related to SWB.

Research has shown that all the Big Five dimensions are consistently associated to SWB and its components in different degrees (Albuquerque et al. 2012; Argyle 1999; Cheng and Furnham 2001; DeNeve and Cooper 1998; Diener et al. 1999; Diener and Lucas 1999; Diener et al. 2003; Grant et al. 2009; Gutiérrez et al. 2005; Hayes and Joseph 2003; Steel et al. 2008).

In context of social ecological model, authors suggest that personal projects features are relevant to SWB (Little 1999a, b, 2007: Little and Chambers 2000). Several studies show that both cognitive (i.e., meaning, efficacy, progress, community) and affective factors (i.e., positive affect, negative affect), which emerge from personal projects appraisals, appear as predictors of SWB (Albuquerque 2006; Pychyl and Little 1998; McGregor and Little 1998; Díaz-Morales and y Sánchez-López 2001). Specifically, the personal projects' efficacy, that is, how likely one's projects are to be successful, was found to be one significant predictor of SWB (Little 1989; Wilson 1990; McGregor and Little 1998). 
Previous research established clear links between Big Five and the content and appraisal of personal projects (Little et al. 1992). Concerning the interaction between Big Five and personal projects on the production of overall happiness (a similar concept to SWB), the compatibility between social traits (extraversion, agreeableness and reversed-scored conscientiousness) and social goals (personal projects related with social themes) was associated with overall happiness. In addition, a mediation analysis suggested that overall social trait-goal compatibility predicted goal enjoyment and manageability which in turn predicted overall happiness (McGregor et al. 2006).

\section{The Present Study}

Although theoretical and empirical evidence support the linkages between personality traits and well-being, as well as between goals and well-being, and claim the importance of the compatibility between traits and goals to well-being, it remains unclear whether personality domains are indirectly linked to well-being through their impact on goals. Therefore the present study aims at clarifying the interplay between level 1 and level 2 of personality of McAdams' model on the production of SWB, and to test some aspects of the relationships between traits, personal projects and well-being preconized by social ecological model (Little 2007). This research is thus interested in expanding prior research by: (1) developing a more complex conceptual model; (2) testing the mediator effect of personal projects' efficacy on the relationship between Big Five and SWB components; and (3) using path analyses, a more powerful statistical technique based on structural equation modelling, to organize an integrated study about the impact of the two different levels of personality on SWB components. It is expected that extraversion, openness to experience, agreeableness and conscientiousness would be associated with increased levels of life satisfaction and positive affect and with increased personal projects' efficacy. In contrast, we predict that these four personality domain would be related to diminished levels of negative affect. Concerning neuroticism domain, we predict that it would be associated with augmented levels of negative affect and decreased levels of life satisfaction, positive affect and personal projects' efficacy. Additionally, we hypothesize that the Big Five would impact upon SWB components through their effect upon personal projects' efficacy (see Fig. 1).

Fig. 1 The conceptual model. $N$ neuroticism, $E$ extraversion, $O$ openness to experience, $A$ agreeableness, $C$ conscientiousness, $P P E$ personal projects' efficacy, $L S$ life satisfaction, $P A$ positive affect, $N A$ negative affect

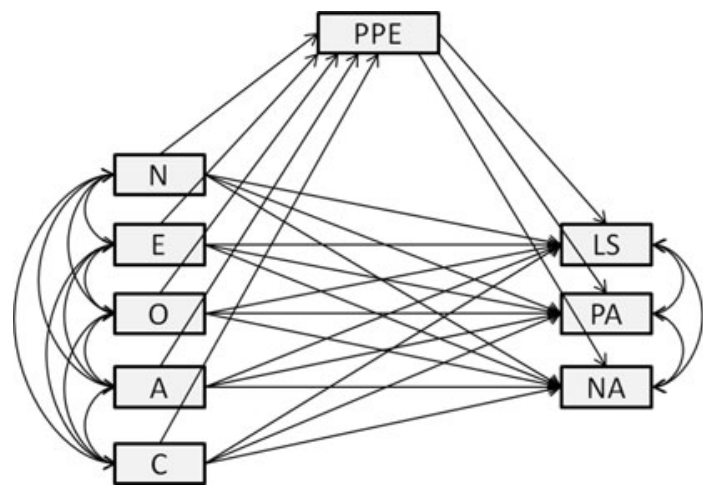




\section{Method}

\subsection{Participants and Procedure}

Participants in this study were 396 teachers (285 woman and 111 men) of primary and high schools from Viseu district (Portugal), randomly selected by clusters corresponding to the schools they worked in. Mean age was 41.09 years $(S D=7.71)$. The majority of subjects were married $(75.6 \%, n=301)$ and $78.95 \%$ graduated $(n=314)$. The average of years of teaching experience was $16.85(S D=8.00)$.

We contacted schools' boards and obtained permission for data collection. With the collaboration of school staff, the author (IA) gave participants a battery of self-report questionnaires related to personality and well-being measures and socio-demographic and professional data, as well as information about the research goals and filling instructions. It was emphasized that participants cooperation was voluntary and that answers were confidential and only used for the purpose of the study.

\subsection{Measures}

\subsubsection{Big Five Domains of Personality}

The five domains of personality were measured with the self-report version of $N E O$ Personality Inventory-Revised (NEO PI-R, Costa and McCrae 1992; Portuguese validation by Lima 1997). The inventory includes a 240-item questionnaire that assesses Big Five personality domains (Neuroticism-N, Extraversion-E, Openness to ExperienceO, Agreeableness-A, and Conscientiousness-C), as well as 6 more specific traits facets within each domain. Answers were given in a Likert scale ranging from 0 (strongly disagree) to 4 (strongly agree). High scores in neuroticism define individuals who are worrying, nervous, emotional, insecure, inadequate, hypochodriacal; high scores in extraversion characterize individuals who are sociable, active, talkative, person oriented, optimistic, fun-loving, affectionate; individuals that present high scores in openness to experience are curious, with broad interests, creative, original, imaginative, untraditional; high scores in agreeableness characterize soft-hearted, good-natured, trusting, helpful, forgiving, gullible, straightforward individuals; high scores in conscientiousness define individuals who are organized, reliable, hard-working, self-disciplined, punctual, scrupulous, neat, ambitious persevering (Costa and McCrae 1992). Internal consistency values for these personality domains are reported in Table 1.

\subsubsection{Personal Projects' Efficacy}

Personal projects' efficacy was assessed through an adapted Personal Projects Analysis (PPA, Little 1983; Portuguese version by Lima 2002). PPA incorporates four modules for personal projects analysis: elicitation, appraisal, hierarchy, and impact. This study used only the first and second modules. In the personal project elicitation module, the respondents were encouraged to generate their planned or ongoing projects without constraint. In the second module, participants selected seven projects that better defined who they are. Then the selected personal projects were appraised in several cognitive dimensions (e.g., importance, challenge, absorption, support, competence, progress...), as well in affective dimensions (e.g., sad, angry, hopeful, depressed, full of love...) in a rating scale from 0 to 10 . A principal component analysis 
(PCA) conducted in a Portuguese sample indicated that cognitive dimensions as competence, control, outcomes, but also autonomy and responsibility, integrated the factor efficacy (Albuquerque and Lima 2012). Only this cognitive factor will be used in this study. High scores in personal projects' efficacy characterizes individuals who have a sense of competence in development of their projects, feel they have control over them, expect good results from them, believe to have autonomy to carry out the projects and feel responsible for its achievement. Cronbach' alpha for efficacy in this sample is shown in Table 1.

\subsubsection{Subjective Well-Being}

SWB was assessed by two self-report measures: Satisfaction with Life Scale (SWLS) and Positive and Negative Affect Schedule (PANAS).

7.2.3.1 SWLS SWLS was designed to appraise the cognitive component of SWB (Diener et al. 1985; Portuguese validation by Simões 1992) that is, individuals' global judgments of their life. SWLS comprises 5 items rated on a Likert scale ranging from 1 (strongly disagree) to 5 (strongly agree), assessing how individuals weight domains of their lives in terms of their own values, in order to reach a global subjective judgment of life satisfaction (Pavot and Diener 1993). High scores in life satisfaction indicate that individuals are globally satisfied with their lives.

7.2.3.2 PANAS PANAS integrates two subscales, Positive Affect (PA) and Negative Affect (NA), which assess the affective component of SWB (Watson et al. 1988; Portuguese validation by Simões 1993). Answers were given in a rating scale from 1 (very slightly or not of all) to 5 (extremely). High scores in PA reflect feelings of enthusiasm, happiness, activation and alert, whereas high scores in NA is indicate several aversive mood states such as anger, contempt, disgust, guilt, fear and nervousness (Watson et al. 1988).

A confirmatory factorial analysis that tested SWB structure (Albuquerque et al. 2012a), suggested a three factor model with 5 items in SWLS, 9 items in PA of PANAS and 9 items in NA of PANAS. Table 1 presents Cronbach'alphas for SWLS, PA and NA.

\section{Results}

\subsection{Statistical Analysis}

Data analyses were conducted using PASW (v. IBM SPSS Statistics 20) and AMOS was used to estimate path analyses (v. IBM SPSS AMOS 20).

A mediational study was then conducted, in which we tested whether personal projects' efficacy (PPE) (mediator variable) mediated the relationship between neuroticism $(\mathrm{N})$, extraversion (E), openness to experience (O), agreeableness (A) and conscientiousness (C) (independent, exogenous variables) and life satisfaction (LS), positive affect (PA) and negative affect (NA) (dependent, endogenous variables).

A path analysis was carried out to test for the mediator effects described above. This technique is a special case of structural equation modeling (SEM) and considers hypothetic causal relations between variables that have already been defined. A Maximum Likehood method was used to evaluate the regression coefficients significance. SEM procedure 
Table 1 Means $(M)$, standard deviations $(S D)$, Independent samples $t$ tests for men and women and Cronbach' alphas for all self-report measures

\begin{tabular}{|c|c|c|c|c|c|c|c|c|c|}
\hline & \multicolumn{2}{|l|}{ Total } & \multicolumn{2}{|l|}{ Males } & \multicolumn{2}{|c|}{ Females } & \multirow[t]{3}{*}{$t$} & \multirow[t]{3}{*}{$p$} & \multirow[t]{3}{*}{$\alpha$} \\
\hline & \multicolumn{2}{|c|}{$(N=396)$} & \multicolumn{2}{|c|}{$(n=111)$} & \multicolumn{2}{|c|}{$(n=285)$} & & & \\
\hline & $M$ & $S D$ & $M$ & $S D$ & $M$ & $S D$ & & & \\
\hline Neuroticism & 93.60 & 20.91 & 90.17 & 19.13 & 94.93 & 21.45 & -2.04 & .042 & .91 \\
\hline Extraversion & 108.98 & 17.83 & 109.06 & 17.16 & 108.95 & 18.11 & 0.05 & .959 & .88 \\
\hline Openness to experience & 113.98 & 15.82 & 111.80 & 15.48 & 114.83 & 15.89 & -1.72 & .087 & .85 \\
\hline Agreeableness & 124.94 & 13.21 & 122.07 & 12.98 & 126.06 & 13.16 & -2.72 & .007 & .79 \\
\hline Conscientiousness & 125.81 & 17.74 & 122.63 & 19.62 & 127.05 & 16.83 & -2.09 & .038 & .99 \\
\hline Personal projects' efficacy & 36.74 & 5.80 & 37.66 & 5.84 & 36.39 & 5.75 & 1.96 & .050 & .84 \\
\hline Life satisfaction & 17.08 & 4.42 & 17.46 & 4.08 & 16.94 & 4.55 & 1.06 & .292 & .84 \\
\hline Positive affect & 32.23 & 4.17 & 31.69 & 3.94 & 32.44 & 4.24 & -1.62 & .107 & .79 \\
\hline Negative affect & 19.86 & 6.27 & 18.89 & 5.78 & 20.24 & 6.42 & -1.93 & .055 & .86 \\
\hline
\end{tabular}

estimates the optimal effect of one set of variables on another set of variables in the same equation, controlling for error (Byrne 2001; Kline 2011). Multivariate outliers were screened using Mahalanobis squared distance (D2) method and uni and multivariate normality was assessed by skewness and kurtosis coefficients. There was no severe violation of normal distribution ( $|\mathrm{Sk}|<3$ and $|\mathrm{Ku}|<8-10)$ (Kline 2011). The significance of direct, indirect and total effects was assessed using $\chi^{2}$ tests (Kline 2011). Bootstrapping resampling method was further used to test the significance of the mediational paths, using 2000 bootstrap samples and 95\% confidence intervals (CIs) (Kline 2011).

Effects with $p<.050$ were considered statistically significant.

\subsection{Descriptives}

The means, standard deviations and Cronbach' alphas for this study variables are presented on Table 1. All scales showed good to excellent internal consistence. We conducted independent samples $t$ test to explore gender differences in the variables studies (Table 1). Results showed that women had statistically significant higher scores than men in neuroticism, agreeableness and conscientiousness. This pattern is similar to the one reported for men and women in the Portuguese NEO PI R validation (Lima 1997). However, because examining gender differences was not an aim of this study and the number of participants was unsatisfactory to test the hypothesized model separately in males and females (Kline 2011), all subsequent analysis were conducted in the total sample.

\subsection{Path Analysis}

According our hypotheses, we aimed at testing whether personal projects' efficacy mediated the effect of neuroticism, extraversion, openness to experience, agreeableness and conscientiousness, on life satisfaction, positive affect and negative affect.

The hypothesized model was tested through a fully saturated model (i.e., zero degrees of freedom), consisting of 45 parameters. Given that fully saturated models always produce a perfect fit to the data, model fit indices were neither examined nor reported. The model explained $19 \%$ of life satisfaction, $38 \%$ of positive affect and $44 \%$ of negative affect 
variances. In this model the following paths were not statistically significant: the direct effect of extraversion on personal projects efficacy $\left(b_{\mathrm{E}}=.029 ; S E_{b}=.019 ; Z=1.520\right.$; $\left.p=.129 ; \beta_{\mathrm{E}}=.090\right)$, the direct effect of extraversion on negative affect $\left(b_{\mathrm{E}}=-.020\right.$; $\left.S E_{b}=.017 ; Z=-1.153 ; p=.249 ; \beta_{\mathrm{E}}=-.057\right)$, the direct effect of openness to experience on life satisfaction $\left(b_{\mathrm{O}}=-.019 ; S E_{b}=.015 ; Z=-1.228 ; p=.219 ; \beta_{\mathrm{O}}=\right.$ $-.068)$, the direct effect of openness to experience on life satisfaction $\left(b_{\mathrm{O}}=-.020\right.$; $\left.S E_{b}=.015 ; Z=-1.309 ; p=.191 ; \beta_{\mathrm{O}}=-.068\right)$, the direct effect of agreeableness on life satisfaction $\left(b_{\mathrm{A}}=-.011 ; S E_{b}=.016 ; Z=-.673 ; p=.501 ; \beta_{\mathrm{A}}=-.032\right)$, the direct effect of agreeableness on negative affect $\left(b_{\mathrm{A}}=-.005 ; S E_{b}=.019 ; Z=-.265\right.$; $\left.p=.791 ; \beta_{\mathrm{A}}=-.011\right)$, the direct effect of conscientiousness on negative affect $\left(b_{\mathrm{C}}=\right.$ $\left.-.006 ; S E_{b}=.016 ; Z=-355 ; p=.722 ; \beta_{\mathrm{C}}=-.016\right)$. Thus, we excluded these nonsignificant paths and recalculated the model. In this second model, three paths emerged as non-significant: the direct effect of extraversion on life satisfaction $\left(b_{\mathrm{E}}=.020\right.$; $\left.S E_{b}=.013 ; Z=1.593 ; p=.111 ; \beta_{\mathrm{E}}=.081\right)$, the direct effect of openness to experience on negative affect $\left(b_{\mathrm{O}}=.027 ; S E_{b}=.016 ; Z=1.756 ; p=.079 ; \beta_{\mathrm{O}}=.069\right)$ and the direct effect of conscientiousness on life satisfaction $\left(b_{\mathrm{C}}=.024 ; S E_{b}=.013 ; Z=1.890\right.$; $\left.p=.059 ; \beta_{\mathrm{C}}=.096\right)$.

For this reason, these three non-significant paths were removed and the model recalculated (Fig. 2). In the evaluation of the adjusted model, a non significant Chi-square test of $16.112\left[\chi_{(9)}^{2} p=.065\right)$ was found. Well-known and recommended goodness of fit indices were selected to assess the model fit (Kline 2011). The analysis of these indices indicated a very good model fit $(\mathrm{CMIN} / \mathrm{DF}=1.790 ; \quad \mathrm{CFI}=.993 ; \quad$ TLI $=.970$; $\mathrm{NFI}=.984$; RMSEA $=.045$ ).

All the paths were statistically significant and the model accounted for $17 \%$ of life satisfaction, $37 \%$ of positive affect and $43 \%$ of negative affect variances. The model also accounted for $18 \%$ personal projects' efficacy variance. The mediator, personal projects' efficacy, predicted directly heightened life satisfaction (.145) and positive affect (.094) and diminished negative affect (-.099). Extraversion (E) only showed a direct effect on positive affect of .272 and had no significant effect on the mediator variable, so no mediator effects were found concerning this variable.

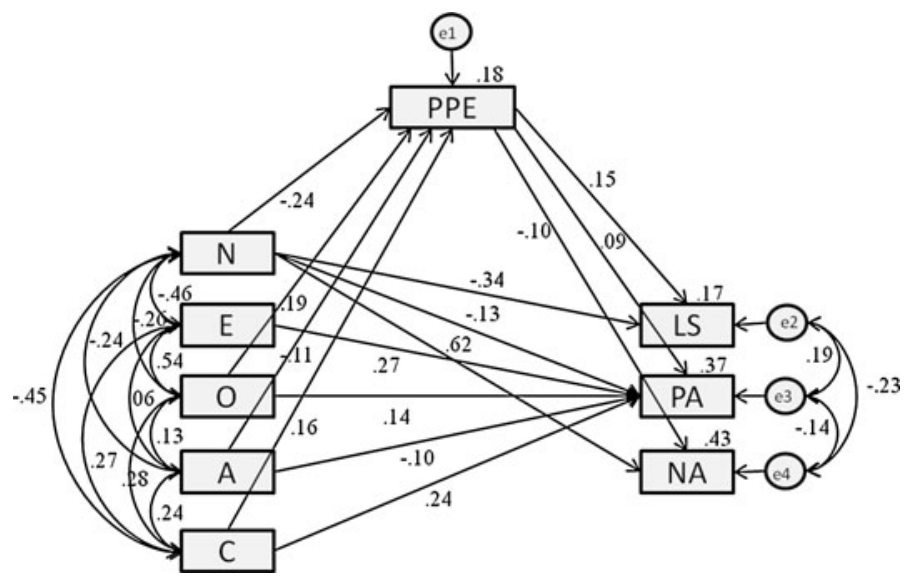

Fig. 2 Results of mediation path analysis showing the relationship among the Big Five personality domains ( $N$ neuroticism, $E$ extraversion, $O$ openness to experience, $A$ agreeableness, $C$ conscientiousness) and SWB components ( $L S$ life satisfaction, $P A$ positive affect, $N A$ negative affect), having PPE (personal projects' efficacy) as mediator, with standardized estimates $(N=396)$ 
In regard to life satisfaction (LS), indirect mediational test results suggest that higher neuroticism predicted lesser life satisfaction partially through diminished personal projects' efficacy (PPE) $\left(b_{\mathrm{N}}=-.035,95 \% \mathrm{CI}=-.063\right.$ to -.011$)$ and also revealed a direct effect of -.342 . Openness to experience $(\mathrm{O})$ indirectly predicted increased life satisfaction fully through greater personal projects' efficacy $\left(b_{\mathrm{O}}=.027,95 \% \mathrm{CI}=.008\right.$ to .049$)$. Agreeableness (A) predicted diminished life satisfaction fully through reduced personal projects' efficacy $\left(b_{\mathrm{C}}=-.015,95 \% \mathrm{CI}=-.033\right.$ to -.002$)$. Conscientiousness (C) also predicted heightened life satisfaction fully through increased personal projects' efficacy $\left(b_{\mathrm{C}}=.023,95 \% \mathrm{CI}=.004\right.$ to .049$)$.

Positive affect (PA) is the only outcome variable in which all personality domains have a direct effect: -.128 for neuroticism, .272 for extraversion, .141 for openness to experience, -.098 for agreeableness and .224 for conscientiousness. Additionally, neuroticism indirectly predicted lower levels of positive affect, partially through diminished personal projects' efficacy $(-.023,95 \% \mathrm{CI}=-.048$ to -.002$)$. Openness to experience predicted increased positive affect partially through greater personal projects' efficacy $(.018,95 \%$ $\mathrm{CI}=.001$ to .039). Conscientiousness indirectly predicted increased positive affect partially through heightened personal projects' efficacy $(.015,95 \% \mathrm{CI}=.001$ to .037$)$. Agreeableness indirectly predicted diminished positive affect partially through a decreased personal projects' efficacy $(-.010,95 \% \mathrm{CI}=-.026$ to .000$)$.

Regarding negative affect, only greater neuroticism directly predicted increased negative affect (.616). This personality domain also indirectly predicted negative affect partially through lowered personal projects' efficacy $(.024,95 \% \mathrm{CI}=.005$ to .044$)$. Agreeableness indirectly predicted increased negative affect fully through diminished personal projects' efficacy $(.011,95 \% \mathrm{CI}=.000$ to .025$)$. In contrast, openness to experience indirectly predicted lesser negative affect fully through increased personal projects' efficacy $(-.019,95 \%$ $\mathrm{CI}=-.038$ to -.004$)$. Conscientiousness indirectly predicted diminished negative affect fully through increased personal projects' efficacy $(-.016,95 \% \mathrm{CI}=-.036$ to -.002$)$.

Figure 2 presents the mediation model with regression coefficients standardized estimates and $R^{2}$ for life satisfaction, positive affect, negative affect and personal projects' efficacy.

In conclusion, these findings indicate that personal projects' efficacy fully mediated the effects of openness to experience, agreeableness and conscientiousness on life satisfaction and on negative affect. Besides, the effects of neuroticism, openness to experience, agreeableness and conscientiousness on positive affect were direct but also indirect, partially mediated by personal projects' efficacy. Neuroticism had a direct and an indirect effect through a decreased personal projects' efficacy on the three components of SWB, diminishing life satisfaction and positive affect, and increasing negative affect. Extraversion only directly predicted increased positive affect.

\section{Discussion}

Comprehensive models that intend to integrate the study of personality in a coherent whole consider that there may be an interplay between its several levels (Little 2007, 2008; Sheldon 2004, 2007, 2009). One of the great research challenges for both the field of personality and the field of well-being is to understand if and how different levels of personality interrelate on the production of well-being. Our premise is that this interrelation can be conceptualized considering goals (level 2 of McAdams' model) as an intermediary process that leads from dispositional traits (level 1 of McAdams' model) to human 
well-being. Accordingly, the current research sought out to explore an integrative model, in which we tested the mediator effect of personal projects' efficacy on the relationship between Big Five domains of personality and the three SWB components. Our findings effectively support the hypothesis that the personal projects' efficacy has a mediator effect on the relationship between personality domains and life satisfaction, positive affect and negative affect. However, some specificities emerged in the pattern of direct and indirect effects.

First, our findings reveal that all Big Five directly or/and indirectly predict all SWB components, with the exception of extraversion, which only revealed a direct effect on positive affect. Then, our most enduring personality structure, that comprises internal and more decontextualized and nonconditioned dimensions, seems to have an essential role in the way we subjectively appraise our lives.

Although previous research refers that neuroticism and extraversion are the strongest predictors of SWB (Argyle 1999; Cheng and Furnham 2001; Diener and Lucas 1999; Gutiérrez et al. 2005; McCrae and John 1992; Vittersø and Nilsen 2002; Schimmack et al. 2002), the present study also points the other three personality domains (openness to experience, agreeableness and conscientiousness) as meaningful predictors of all SWB components. This confirms the power of dispositional traits in the explanation of SWB and corroborates Lucas and Diener' consideration concerning the impact of personality traits, who note that "the most important factor in determining a person's SWB appears to be the personality with which he or she is born" (Lucas and Diener 2008, p. 801). Moreover, the current results allow us to appreciate how the several personality domains influence the three SWB components when their effects are considered simultaneously.

Second, the current study also revealed that personal projects' efficacy, which represent personal action constructs (level 2 of McAdams' model), that is a unit of personality analysis more contextualized in time and space than traits, can have a mediator role on the relationship between personality dimensions and SWB. These findings are in line with some authors' conceptualization regarding the relations among traits and goals (Little 2007, 2008; Sheldon 2004, 2009). In fact, path analysis results showed that personal projects' efficacy emerged as a significant mediator of personality domains influence on three SWB components. So, the sense of competence and control, and the anticipation of positive outcomes about our planned or on-going personal projects emerge a possible way through which personality dimensions influence SWB components.

As expected, emotional instability characterized by anxiety, depression, hostility, vulnerability, self-consciousness, impulsiveness (i.e., neuroticism) (Costa and McCrae 1992, 2008) directly and indirectly predicted diminished life satisfaction and positive affect through lowered personal projects' efficacy. In contrast, neuroticism predicted increased negative affect both directly and indirectly. Extraversion, characterized by an energetic approach toward the social and material world (John et al. 2008), including traits such as activity, positive emotions, gregariousness, assertiveness, warmth, and excitement-seeking (Costa and McCrae 1992), only had a direct effect on positive affect, increasing this SWB component. Openness to experience, which describes the breadth, depth, originality and complexity of mental and experiential life (John et al. 2008) and comprises traits such as ideas, aesthetics, fantasy, actions, feelings and values in which individuals are open (Costa and McCrae 1992), indirectly predicted heightened life satisfaction and diminished negative affect fully through personal projects' efficacy. In addition, this personality domain predicted increased positive affect directly and indirectly through personal projects' efficacy. Contrary to our expectation, agreeableness, characterized by a prosocial and communal orientation (John et al. 2008) and containing traits such as modesty/humility, trust, 
tender-mindedness, compliance and straightforwardness (Costa and McCrae 1992), directly and indirectly predicted lowered positive affect. Moreover, this personality domain indirectly predicted diminished life satisfaction and increased negative affect fully through personal projects' efficacy. Finally, our personality domain linked to impulse control and to thinking before acting, delaying gratification, following rules and norms, planning, organizing and prioritizing tasks, that is conscientiousness (John et al. 2008), predicted heightened life satisfaction and decreased negative affect fully through personal projects' efficacy. In addition, this personality domain directly and indirectly predicted increased positive affect.

McAdams and Pals (2006) suggested that each personality level is not reducible to other levels and that each level provides relevant information. In his social ecological model of personality, Little $(2007,2008)$ proposed the existence of a direct effect of both personality dimensions and personal projects and an indirect effect of personality dimensions through personal projects' features on human well-being. Our results give support to this perspective. Thus, SWB can be explained by levels of personality in distinct ways. Despite personality dimensions influence SWB through personal projects' efficacy, personality domains and personal projects efficacy can have their own effects, unique and irreducible. Moreover, other studies using different constructs from each level of personality suggested a similar type of influence on well-being (Sheldon and Hoon 2007). More recently, findings from a longitudinal study about the genetic and environmental sources of the interplay between Big Five and major life goals also support the plausibility of this idea (Bleidorn et al. 2010).

The present data may have relevant implications to the study of personality. In particular, these two types of personality analysis units appear to have a unique and irreducible effect on SWB. Furthermore, the effect of personality dimensions on SWB components seems to be also explained, fully or partially, through personal action constructs features.

\subsection{Limitations and Future Research}

This study was conducted in a teachers sample and this can constitute a methodological limitation to the generalization of our results. The overrepresentation of certain groups limits the generalization to other populations (Brewer 2000), so future studies should be developed using larger and heterogeneous samples. Although gender differences emerged in our study in some personality domains, they were not further investigated. In the future, studies should seek to replicate the integrative model presented here testing for gender differences.

In addiction, the cross-sectional design of the study doesn't allow drawing conclusions about the inter-relationship between the Big Five and personal projects' efficacy across time on prediction of SWB components. Longitudinal studies could help to overcome this problem.

Others studies should test the mediator role of other features of goals on these relationships. Moreover, future research should integrate variables of level 3 of personality study, that is, self-narrative variables, drawing a more complete picture of the interrelation between the three levels on production of well-being.

\section{Conclusion}

The findings presented here strengthen the theoretical assumption which postulates the existence of relationships among the different levels of personality analysis on the 
production of several life outcomes, specifically of human well-being. Additionally, they also confirm that each personality level of McAdams model has its own pertinence to several SWB components. To understand a person as a whole, a comprehensive framework that considers several levels of personality analysis is required.

\section{References}

Albuquerque, I. (2006). O florescimento dos professores: Projectos pessoais, bem-estar subjectivo e satisfação profissional. Unpublished master's thesis, University of Coimbra, Coimbra.

Albuquerque, I., \& Lima, M. P. (2012). Os projectos pessoais: Análise factorial exploratória numa amostra portuguesa, In preparation.

Albuquerque, I., Lima, M. P., Figueiredo, C., \& Matos, M. (2012). Subjective well-being structure: Confirmatory factor analysis in a Portuguese teacher sample. Social Indicators Research, 105, 569-580.

Albuquerque, I., Lima, M. P., Matos, M., \& Figueiredo, C. (2012b). Personality and subjective well-being: What hides behind global analyses? Social Indicators Research, 105, 447-460. doi:10.1007/s11205010-9780-7.

Argyle, M. (1999). Causes and correlates of happiness. In D. Kahneman, E. Diener, \& N. Schwarz (Eds.), Well-being: The foundations of hedonic psychology (pp. 213-229). New York: Russell Sage Foundation.

Bleidorn, W., Kandler, C., Hülsheger, U. R., Riemann, R., Angleitner, A., \& Spinath, F. M. (2010). Nature and nurture of the interplay between personality traits and major life goals. Journal of Personality and Social Psychology, 99, 366-379.

Brewer, M. B. (2000). Research design and issues of validity. In H. T. Reis \& C. M. Judd (Eds.), Handbook of research methods in social and personality psychology (pp. 3-16). Cambridge: Cambridge University Press.

Brunstein, J. C., Schultheiss, O. C., \& Grässman, R. (1998). Personal goals and emotional well-being: The moderating role of motive dispositions. Journal of Personality and Social Psychology, 75, 494-508.

Buss, D. M. (1995). Evolutionary psychology: A new paradigm for psychological science. Psychological Inquiry, 6, 1-31.

Buss, D. M. (2009). How can evolutionary psychology successfully explain personality and individual differences? Perspectives on Psychological Sciences, 4, 359-366.

Byrne, B. (2001). Structural equation modeling with amos:basic concepts, applications and programming. New Jersey: Lawrence Erlbaum Associates.

Cantor, N., \& Kihlstrom, J. F. (1987). Personality and social intelligence. Englewood Cliffs, N.J.: PrenticeHall.

Cheng, H., \& Furnham, A. (2001). Attributional style and personality as predictors of happiness and mental health. Journal of Happiness Studies, 2, 307-327.

Costa, P. T., Jr., \& McCrae, R. R. (1992). Revised NEO personality inventory (NEO-PI-R) and NEO fivefactor inventory (NEO-FFI). Odessa, FL: Psychological Assessment Resources, Inc.

Costa, P. T., Jr., \& McCrae, R. R. (2008). The revised NEO personality inventory (NEO-PI-R). In G. J. Boyle, G. Matthews, \& D. H. Saklofske (Eds.), The sage book of personality theory and assessment (Vol. 2, pp. 179-198). London: Sage Publications.

Costa, P. T., Terracciano, A., \& McCrae, R. R. (2001). Gender differences in personality traits across cultures: Robust and surprising findings. Journal of Personality and Social Psychology, 81, 322-331.

Deci, E. L., \& Ryan, R. M. (2008). Hedonia, eudaimonia, and well-being: An introduction. Journal of Happiness Studies, 9, 1-11.

DeNeve, K. M., \& Cooper, H. (1998). The happy personality: A meta-analysis of 137 personality traits and subjective well-being. Psychological Bulletin, 95, 542-575.

Díaz-Morales, J. F., \& y Sánchez-López, M. P. (2001). Relevancia de los estilos de personalidad y las metas personales en la predicción de la satisfacción vital. Anales de psicología, 17, 151-158.

Diener, E. (1984). Subjective well-being. Psychological Bulletin, 95, 542-575.

Diener, E. (2000). Subjective well-being: The science of happiness and proposal for a national index. American Psychologist, 55, 34-43.

Diener, E., Emmons, R. A., Larsen, R. J., \& Griffin, S. (1985). The satisfaction with life scale. Journal of Personality Assessment, 49, 71-75.

Diener, E., \& Fujita, F. (1995). Resources, personal strivings, and subjective well-being: A nomothetic and idiographic approach. Journal of Personality and Social Psychology, 68, 926-935. 
Diener, E., \& Lucas, R. E. (1999). Personality and subjective well-being. In D. Kahneman, E. Diener, \& N. Schwarz (Eds.), Well-being: The foundations of hedonic psychology (pp. 213-229). New York: Russel Sage Foundation.

Diener, E., Lucas, R. E., \& Oishi, S. (2002). Subjective well-being: The science of happiness and life satisfaction. In C. R. Snyder \& S. J. Lopez (Eds.), The handbook of positive psychology (pp. 63-73). New York: Oxford University Press.

Diener, E., Oishi, S., \& Lucas, R. E. (2003). Personality, culture, and subjective well-being: Emotional and cognitive evaluations of life. Annual Review of Psychology, 54, 403-424.

Diener, E., \& Suh, M. E. (1997). Measuring quality of life: Economic, social, and subjective indicators. Social Indicators Research, 40, 189-216.

Diener, E., \& Suh, M. E. (1998). Subjective well-being and age: An international analysis. Annual Review of Gerontology and Geriatrics, 17, 304-324.

Diener, E., Suh, E. M., Lucas, R. E., \& Smith, H. L. (1999). Subjective well-being: Tree decades of progress. Psychological Bulletin, 125, 276-302.

Eid, M., \& Larsen, R. J. (Eds.). (2008). The science of subjective well-being. London: The Guilford Press.

Emmons, R. A. (1986). Personal strivings: An approach to personality and subjective well-being. Journal of Personality and Social Psychology, 51, 1058-1068.

Grant, S., Langan-Fox, J., \& Anglim, J. (2009). Big five traits as predictors of subjective and psychological well-being. Psychological Reports, 105, 201-231.

Gutiérrez, J. L. G., Jiménez, B. M., Hernandez, E. G., \& Puente, C. P. (2005). Personality and subjective well-being: Big five correlates and demographic variables. Personality and Individual Differences, 38 , 1561-1769.

Hayes, N., \& Joseph, S. (2003). Big 5 correlates of tree measures of subjective well-being. Personality and Individual Differences, 34, 723-727.

Hooker, K., \& McAdams, D. P. (2003). Personality reconsidered: A new agenda for aging research. The Journal of Gerontology, 58B(6), 296-304.

John, O. P., Naumann, L. P., \& Soto, C. J. (2008). Paradigm shift to the integrative big-five trait taxonomy: History, measurement, and conceptual issues. In O. P. John, R. W. Robins \& L. A. Pervin (Eds.), Handbook of personality: Theory and research (pp. 114-158). New York, NY: Guilford Press.

Kahneman, D., Diener, E., \& Schwartz, N. (Eds.). (1999). Well-being: The foundations of hedonic psychology. New York: Russell Sage Foundation.

Kline, R. B. (2011). Principles and practice of structural equation modeling (3rd ed.). New York: The Guilford Press.

Klinger, E. (1975). Consequences of commitment to and disengagement from incentives. Psychological Review, 82(1), 1-25.

Klinger, E. (1977). Meaning and void: Inner experience and the incentives in people's lives. Minneapolis, MN: University of Minnesota Press.

Lima, M. P. (1997). NEO-PI-R: Contextos teóricos e psicométricos. “Ocean” ou "iceberg”. Unpublished PhD's thesis, University of Coimbra, Coimbra.

Lima, M. P. (2002). Personal projects analysis (Portuguese version for research). Coimbra: Faculty of Psychology and Education Sciences, University of Coimbra.

Little, B. R. (1983). Personal projects: A rationale and method for investigation. Environment and Behavior, $15,173-309$.

Little, B. R. (1989). Personal projects analysis: Trivial pursuits, magnificent obsessions, and search of coherence. In D. M. Buss \& N. Cantor (Eds.), Personality psychology: Recent trends and emerging directions (pp. 15-31). New York: Springer.

Little, B. R. (1996). Free traits, personal projects and idio-tapes: Three tiers for personality psychology. Psychological Inquiry, 7, 340-344.

Little, B. R. (1999a). Personal projects and social ecology. In J. Brandstadter \& R. Learner (Eds.), Action and self-development: Theory and research through the lifespan (pp. 197-221). Thousand Oaks, CA: Sage.

Little, B. R. (1999b). Personality and motivation: Personal action and conative evolution. In L. A. Pervin \& O. P. John (Eds.), Handbook of personality: Theory and research (2nd ed., pp. 501-524). New York: The Guilford Press.

Little, B. R. (2000). Free traits and personal contexts: Expanding a social ecological model of well-being. In W. B. Walsh, K. H. Craik, \& R. Price (Eds.), Person environment psychology (2nd ed., pp. 87-116). New York: The Guilford Press.

Little, B. R. (2004). Personality psychology: Havings, doings and beings in context. Available in http:// www.brianrlittle.com/articles/havings_doings_beings.htm/. 
Little, B. R. (2006). Personality science and self-regulation: Personal projects as integrative units. Applied Psychology: An International Review, 55, 419-427.

Little, B. R. (2007). Prompt and circumstance: Generative contexts of personal projects. In B. R. Little, K. Salmela-Aro, \& S. D. Phillips (Eds.), Personal projects pursuit: Goals, action, and human flourishing (pp. 3-51). New Jersey: Lawrence Erlbaum Associates Publishers.

Little, B. R. (2008). Personal projects and free traits: Personality and motivation reconsidered. Social and Personality Compass, 2, 1235-1254.

Little, B. R., \& Chambers, N. C. (2000). Personal projects analysis: An integrative framework for clinical and counselling psychology. Revue Québecoise de Psychologie, 21, 153-190.

Little, B. R., \& Chambers, N. C. (2004). Personal project pursuit: On human doings and well-beings. In W. Miles Cox \& E. Klinger (Eds.), Handbook of motivational counseling (pp. 65-82). New York: Wiley.

Little, B. R., \& Joseph, M. (2007). Personal projects and free traits: Mutable selves and well-beings. In B. R. Little, K. Salmela-Aro, \& S. D. Phillips (Eds.), Personal projects pursuit: Goals, action, and human flourishing (pp. 375-402). New Jersey: Lawrence Erlbaum Associates Publishers.

Little, B. R., Lecci, L., \& Watkinson, B. (1992). Personality and personal projects: Linking big five and PAC units of analysis. Journal of Personality, 60, 501-525.

Lucas, R. E., \& Diener, E. (2008). Personality and subjective well-being. In O. P. John, R. Robins, \& L. A. Pervin (Eds.), Handbook of personality (2nd ed.). New York: The Guilford Press.

McAdams, D. P. (1992). The five-factor model in personality: A critical approach, Special issue, "The five factor model: Issues and applications". Journal of Personality, 60, 329-357.

McAdams, D. P. (1995). What do we know when we know a person? Journal of Personality, 63, 365-393.

McAdams, D. P. (1996). Personality, modernity, and storied self: A contemporary framework for studying persons. Psychological Inquiry, 7, 295-321.

McAdams, D. P. (2009). The person: An introduction to the science of personality psychology (5th ed.). New York: Wiley.

McAdams, D. P., \& Adler, J. (2006). How does personality develop? In D. Mroczek \& T. Little (Eds.), Handbook of personality development (pp. 469-493). Mahwah, NJ: Lawrence Erlbaum Associates.

McAdams, D. P., \& Olson, B. D. (2010). Personality development: Continuity and change over the life course. Annual Review of Psychology, 61, 517-542.

McAdams, D. P., \& Pals, J. L. (2006). A new big five: Fundamental principles for an integrative science of personality. American Psychologist, 61, 204-217.

McCrae, R. R., \& Costa, P. T., Jr. (1996). Toward a new generation of personality theories: Theoretical contexts for the five factor model. In J. S. Wiggins (Ed.), The five factor model of personality (pp. 58-87). New York: Guilford Press.

McCrae, R. R., \& Costa, P. T., Jr. (1997). Personality trait structure as human universal. American Psychologist, 52, 509-516.

McCrae, R. R., \& Costa, P. T., Jr. (2003). Personality in adulthood: A five-factor theory perspective (2nd ed.). New York: Guilford Press.

McCrae, R. R., \& Costa, P. T., Jr. (2008a). Empirical and theoretical status of the five-factor model of personality traits. In G. J. Boyle, G. Matthews, \& D. H. Saklofske (Eds.), The sage book of personality theory and assessment (Vol. 1, pp. 272-293). London: Sage Publications.

McCrae, R. R., \& Costa, P. T., Jr. (2008b). The five factor theory of personality. In O. P. John, R. W. Robins, \& L. A. Pervin (Eds.), Handbook of personality: Theory and research (3rd ed., pp. 159-181). New York: Guilford Press.

McCrae, R. R., Costa, P. T., Jr., Lima, M. P., Simões, A., Ostendorf, F., Angleitner, A., et al. (1999). Age differences in personality across the adult lifespan: Parallels in five cultures. Developmental Psychology, 35, 466-477.

McCrae, R. R., \& John, O. (1992). An introduction to the five-factor model and its applications. Journal of Personality, 60, 174-214.

McGregor, I., \& Little, B. R. (1998). Personal projects, happiness, and meaning: On doing well and being yourself. Journal of Personality and Social Psychology, 74, 494-512.

McGregor, I., McAdams, D. P., \& Little, B. R. (2006). Personal projects, life stories, and happiness: On being true to traits. Journal of Research in Personality, 40, 551-572.

Mischel, W. (2004). Toward an integrative science of the person (Prefatory Chapter). Annual Review of Psychology, 55, 1-22.

Ozer, D. J., \& Benet-Martínez, V. (2006). Personality and prediction of consequential outcomes. Annual Review of Psychology, 57, 401-421.

Pavot, W., \& Diener, E. (1993). Review of the satisfaction with life scale. Psychological Assessment, 5, $164-172$. 
Pavot, W., Fujita, F., \& Diener, E. (1995). The relation between self-aspect congruence, personality and subjective well-being. Personality and Individual Differences, 22, 183-191.

Pychyl, T. A., \& Little, B. R. (1998). Dimensional specificity in the prediction of subjective well-being: Personal projects in pursuit of the PHD. Social Indicators Research, 45, 423-473.

Roberts, B. W., \& Wood, D. (2006). Personality development in the context of the neo-socioanalytic model of personality. In D. Mroczek \& T. Little (Eds.), Handbook of personality development (pp. 11-39). Mahwah, NJ: Lawrence Erlbaum Associates.

Schimmack, U., Diener, E., \& Oishi, S. (2002). Life-satisfaction is a momentary judgment and a stable personality characteristic: The use of chronically accessible and stable sources. Journal of Personality, $70,345-384$.

Sheldon, K. M. (2002). The self-concordance model of healthy goal-striving: When personal goals correctly represent the person. In E. L. Deci \& R. M. Ryan (Eds.), Handbook of self-determination theory (pp. 65-86). Rochester, NY: University of Rochester Press.

Sheldon, K. M. (2004). Optimal human being: An integrated approach. New Jersey: Lawrence Erlbaum Associates.

Sheldon, K. M. (2007). Considering the optimality of personality: Goals, self-concordance, and multi-level personality integration. In B. R. Little, K. Salmela-Aro, \& S. D Phillips (Eds), Personal projects pursuit: Goals, action, and human flourishing (pp. 355-374). New Jersey: Lawrence Erlbaum Associates Publishers.

Sheldon, K. M. (2009). Providing the scientific backbone for positive psychology: A multi-level conception of human thriving. Psychological Topics, 18, 267-284.

Sheldon, K., \& Hoon, T. (2007). The multiple determination of well-being: Independent effects of positive traits, needs, goals, selves, social supports, and cultural contexts. Journal of Happiness Studies, 8, $565-592$.

Sheldon, K. M., \& Kasser, T. (1998). Pursuing progress: Skills enable progress, but not all progress is beneficial. Personality and Social Psychology Bulletin, 68, 1319-1331.

Simões, A. (1992). Ulterior validação de uma escala de satisfação com a vida (SWLS). Revista Portuguesa de Pedagogia, XXVI, 3, 503-515.

Simões, A (1993). São os homens mais agressivos que as mulheres? Revista Portuguesa de Pedagogia, XXVII, 387-404.

Singer, J. A. (2005). Personality and psychotherapy: Treating the whole person. New York: The Guilford Press.

Steel, P., Schmidt, J., \& Shultz, J. (2008). Refining the relationship between personality and subjective wellbeing. Psychological Bulletin, 134, 138-161.

Vitters $\varnothing$, J., \& Nilsen, F. (2002). The conceptual and relational structure of subjective well-being, neuroticism, and extraversion: Once again, neuroticism is the important predictor of happiness. Social Indicators Research, 57, 89-118.

Watson, D., Clark, L., \& Tellegen, A. (1988). Development and validation of brief measures of positive and negative affect: The PANAS scales. Journal of Personality and Social Psychology, 54, 1063-1070.

Wilson, D. A. (1990). Personal projects dimensions and perceived life satisfaction. Unpublished master's thesis, Carleton University, Otawa. 